\title{
The Effect of Physical Co-Location on Social Competence, Gaming Engagement and Gamer Identity within a Competitive Multiplayer Game
}

\author{
Joanne Powell ${ }^{1,2,{ }^{*}}$, Linda Kaye ${ }^{1}$ \\ ${ }^{1}$ Department of Psychology, Edge Hill University, Ormskirk, UK \\ ${ }^{2}$ Institute of Psychology, Health and Society, University of Liverpool, Liverpool, UK
}

\section{Email address}

joanne.powell@edgehill.ac.uk (J. Powell)

${ }^{*}$ Corresponding author

\section{To cite this article}

Joanne Powell, Linda Kaye. The Effect of Physical Co-Location on Social Competence, Gaming Engagement and Gamer Identity within a Competitive Multiplayer Game. Open Science Journal of Psychology. Vol. 5, No. 4, 2018, pp. 38-44.

Received: June 21, 2018; Accepted: August 17, 2018; Published: September 1, 2018

\begin{abstract}
Playing digital games in the physical co-location of others elicits a different experience than solo play, with the experience of social play often being described as more immersive and fun. The current study investigated in a sample of 40 individuals (mean age $=20.3$ years), the effect of playing a competitive multiplayer game on gaming engagement, gamer identity and social competence; and whether this effect was influenced by the physical location of another player. Results showed that across all participants there was an increase in gamer identity, gaming engagement and social competence. The physical location of another player had a significantly greater effect on social competence than playing alone $(p=0.02)$. However, this was not the case for gamer identity or engagement $(p>0.05)$. A significant positive relationship was found between engagement with identity $(p<0.001)$ but not social competence $(p>0.05)$; an association which held across game condition (i.e. solo and colocated gameplay). The results suggest that location of another player during competitive gameplay improves individuals' selfevaluation of social competence and gaming more generally has positive impacts for players' perceptions of identity.
\end{abstract}

\section{Keywords}

Gamer Identity, Gamer Engagement, Social Competence, Physical Co-located Gameplay

\section{Introduction}

Digital games can be highly social in nature, and often provide players with ample opportunities to interact, cooperate, compete and be socially integrated into networks and communities $[1,2]$. The turn of the $21^{\text {st }}$ Century has seen an explosive increase in games designed as solely multiplayer experiences [3]. The social aspects of play constitute a fundamental motivator for many players [4], and are largely described to enhance the emotional experiences of gaming $[5,6,7]$.

However, "social gaming" comprise a multitude of experiences, such as, playing online with other players; playing online games but not engaging in any form of social interaction or play (often referred to as being "alone together") [8]; or being physically co-located with other players in multiplayer gaming. The current research focuses predominantly on the latter as a form of social play from which to understand its psychosocial impacts. This may constitute what is typically understood as social interaction, including; awareness, involvement and engagement; the result of a complex interplay of compensatory and reciprocal behaviours involving verbal communication, interpersonal distance, body orientation, gesture and gaze direction [9]. Although it is beyond the scope of the current study to establish the specific constitution of physical co-location by these varying dimensions, the current theoretical stance is that the impacts of a co-located partner in a gaming task may vary from those undertaken alone, based on the previous literature, discussed next.

The effect of 'mere presence' or physical co-location of others on individual performance is well established [10]. Research shows performance abilities increase in the 
presence of others, a phenomenon known as 'social facilitation' [11]. For example, Bowman and colleagues found gameplay in the presence of a physical audience predicted game performance [12]. However, social facilitation effects are only found for low challenge games where drive-inducing capacity of task challenge is minimized. Playing digital games with others elicits a different experience than solo play [3, 6, 13, 14] and experience of playing socially is more immersive than playing alone [15]. Additionally, physical co-location is found to influence fun, challenge and perceived competence of players in the game, the quality and nature of the emotions elicited during play $[16,17]$. This is largely because digital gaming is a situated experience, shaped by socio-spatial contingencies [18]. Digital games also provide opportunities for social interaction/conversation and enjoyment that results from playing with others, spectating, and enhanced emotional experience that comes from a crowd [19]. Several studies have demonstrated beneficial effects of gaming on affective and social domains, and cognitive skills [20,21].

The psychological experiences shown to occur during socially co-located gaming have often been explored using the Game Engagement Questionnaire (GEQ) [22], and the Social Presence in Gaming Questionnaire (SPGQ) [9]. These measures quantify the subjective experiences of engagement typically understood to include; immersion, flow, presence and psychological absorption [7, 23-28]. Immersion characterises the ability of the game to induce the experiences of being part of the game environment [23], whereas flow describes feelings of enjoyment that arise when an individual is absorbed in performing an intrinsicallyrewarding task whereby the balance between skill and challenge is achieved [24]. Explanations of flow and immersion experiences consist of descriptions of 'mental absorption, a trance-like state, focus, or loss of awareness of others' [18]. A clear definition of presence is still emerging $[22,29]$, but typically refers to the experience of being inside a virtual environment, while maintaining a normal state of consciousness [29]. Presence is also considered dimensional $[25,29,30]$ in terms of: spatial presence (the sense of being physically located in a virtual environment); social presence (the experience of virtual social actors as though they are actual social actors); and self-presence (a state in which users experience their virtual self as if it were their actual self). For the purposes of the current study, presence is theorised in respect of the original conceptualisation in the GEQ and refer to this as co-location.

Although much previous research has established differential engagement experiences between conditions which vary in co-location of agents $[5,16,17,31]$, and the nature of the gaming task [13], less understood is how these experiences correspond to impacts on psychosocial outcomes. That is, the expected enhancement of engagement in physical co-located gaming tasks, relative to solo, can conceivably have varying psychosocial impacts for perceived social competence and gamer identity. The theoretical mechanisms underpinning this prediction are discussed next.
Social forms of gaming are positively related to player identity which in turn, predicts positive psychosocial wellbeing [2, 32]. In respect of player identity, this is best underpinned by the principles of Social Identity Theory (SIT) [33]. This posits how one's sense of self is influenced by affiliation to a social group (ibid). In the case of social gaming, SIT is a useful framework to understand gamer identity, and operationalize its impact on psychosocial outcomes [34, 35]. Gamer identity derived through involvement in online gaming is positively related to players' perceptions of their social competence and selfesteem but negatively related to loneliness [7, 36, 37]. These studies refer to online gaming, however, not yet established is whether these outcomes are relevant for "offline", physical co-located play, hence present the basis for the current study. One may expect there to be equivalent outcomes, or if anything, a more pronounced effect on identity and social competence in respect of the richness of social cues present in a physical setting relative to online ones. Involvement in co-located play will facilitate sense of identity and have a positive impact on perceptions of social competence, relative to solo play. The current study asked the following research questions (RQs): 1. To what extent does physical co-presence in a competitive gaming task impact upon gaming engagement, identity and social competence? 2. Are there equivalent impacts for solo gaming tasks? 3. To what extent does gaming engagement impact upon identity and social competence and is this influenced by physical co-location?

\section{Methods}

\subsection{Design}

A between-participants design was used in which participants $(N=40)$ were randomly allocated to either solo $(\mathrm{N}=20)$ or co-located $(\mathrm{N}=20)$ conditions. Within-participant analyses were undertaken on measures of gamer identity (FISI), gaming engagement (GEQ) and social competence (SSI) which were obtained before and after the gaming session. In the pre-test, the GEQ was completed in respect of typical experiences of engagement in gaming, and at post-test was in respect of the gaming task of the study.

\subsection{Participants}

Participants $\left(\mathrm{M}_{\mathrm{age}}=20.3, \quad \mathrm{SD}=1.1\right)$ were 11 males $\left(\mathrm{M}_{\mathrm{age}}=20.1, \mathrm{SD}=1.3\right)$ and 29 females $\left(\mathrm{M}_{\mathrm{age}}=20.4, \mathrm{SD}=1.1\right)$, recruited via a University Gaming Society via posters. All participants engaged in online gaming; those who did not were excluded from partaking in the study. The study received approval from the Department of Psychology's Research Ethics Committee. On average participants reported playing 'occasionally' on a weekly basis for $5 \mathrm{hrs} 40 \mathrm{mins}$. Frequency of gameplay per week was associated with an increase in time spent playing games per week $\left(\chi_{(3)}^{2}=25.94\right.$, $p<0.001)$. 


\subsection{Digital Game Stimuli}

The study used Doritos Crash Course which was run on Xbox 360 (Xbox Live Arcade). Doritos Crash Course requires little skill to play, therefore, allowing participants to understand the gaming controls quickly and easily. Players viewed the game through a third-person perspective, in which the avatar is seen side-on. All players were given the same avatar regardless of condition, which move through increasingly difficult obstacle courses. As the character progressed through the course, they moved through check points. If the player falls off course, it begins the course from the last check point passed. Participants completed one course; the end of the gaming session was determined by how long it took to complete. Games can be played in either: single-player mode (solo condition) whereby individual's plays on their own against others online, via a scoring board, which shows the ranking of each player at the end of gameplay; or multiplayer mode (co-located condition) whereby individual's play against another, who is physically next to them, playing on a split screen, and against other individuals online. The player to complete the course in the fastest time wins.

\subsection{Materials}

Participants completed a series of background questions which asked demographic information concerning age and gender, as well as information on their frequency of online gaming. Specifically this asked how regularly they played on an average week (very rarely, occasionally, regularly and most of the time), and for how many minutes on average.

\subsubsection{Gaming Engagement}

Gaming engagement was measured using the Game Engagement Questionnaire (GEQ) [22]. The GEQ consists of 19 statements, used to identify players' typical level of psychological engagement in playing digital games. 'Engagement' is a generic indicator of game involvement and includes immersion (e.g., "I really get into the game"); presence (e.g., "I lose track of time"); flow (e.g., "If someone talks to me I don't hear them"), and psychological absorption (e.g., "I lose track of where I am"). Participants were presented with a series of statements and rated the extent to which they endorsed item on a 7-point scale ( $1=$ Strongly disagree, $7=$ Strongly agree). Brockmyer et al. report Cronbach's alpha to be .85; the Rasch estimate of person reliability was .83 and item reliability was .96 [22].

\subsubsection{Gamer Identity}

Gamer identity was assessed using an adapted version of the Four Item Scale of Social Identification (FISI) [38] which relates specifically to social identification as a gamer. Participants rated the four statements on a 7-point scale (1=Strongly disagree, $7=$ Strongly agree). Items included; "I see myself as a gamer.” Doosje et al. report Cronbach's alpha to be .83 [38].

\subsubsection{Social Competence}

Social competence was assessed using the brief version of the Social Skills Inventory (SSI) [39] consisting of 30 statements which are rates on a 5-point scale (from $1=$ strongly disagree to $5=$ strongly agree). The SSI breaks down basic communication skills into: expressivity, sensitive and control, which operate in two domains: the nonverbal/emotional and the verbal/social, yielding six SSI subscales. Items included; "I am able to liven up a dull party" (emotional expressivity), "I sometimes cry at sad movies" (emotional sensitivity), "I am very good at maintaining a calm exterior even if I am upset" (emotional control), "I usually take the initiative to introduce myself to a stranger" (social expressivity), "I'm generally concerned about the impression I'm making on others" (social sensitivity), and "I can easily adjust to being in just about any social situation" (social control). A global index was shown to have an overall internal consistency reliability of $\alpha=.80$.

\subsection{Procedure}

Participants first completed the demographic questionnaire and pre-test measures of gamer identity (FISI), gaming engagement (GEQ) and social competence (SSI). Participants were randomly assigned to play either individually (solo condition/single-player mode) or in a pair (co-located condition/multiplayer mode). In the co-located condition, participants were asked to confirm that they were not familiar, and had not played, with the other participant previously. Participants were familiarised with the Xbox 360 controllers and the game rules, then given a practice course. When playing the game participants were instructed to complete the course as quickly as possible. Participants finally completed the post-test measures (FISI, GEQ and SSI), before being debriefed.

\subsection{Statistical Analysis}

All statistical analysis was performed in IBM SPSS version 22. A Kruskal-Wallis $\mathrm{H}$ test was used to compare differences in time spent playing games per week (in minutes) across the four categories of game play frequency. Pearson's product moment correlational analysis explored the relationship among: gamer identity, social competence and gamer engagement. Bonferroni correction was applied to the alpha level 0.05 to consider the three correlations being performed (revised alpha level=0.017). Mixed-design ANOVA was performed to test the effect of gameplay on gamer identity, gaming engagement and social competence, across the sample, and to test the effect of condition (i.e. solo/co-located) on change in gamer identity, gaming engagement and social competence (pre- and postgameplay). A multivariate ANOVA was used to test the effect of gaming engagement, condition and the interaction between these two terms on gamer identity and competence using post-gameplay scores. 


\section{Results}

\subsection{Correlational Analysis}

Correlational analysis revealed a significant positive association between gamer identity and engagement $(\mathrm{r}=0.544, P<0.001)$. No significant relationship was found between social competence with gamer identity or engagement $(P>0.017)$.

\subsection{Pre-post Changes (Overall Sample)}

Repeated measures ANOVA revealed there was an overall difference between pre- and post-gameplay for gamer identity $\left(F_{(1,38)}=330.49, p<0.001\right.$, partial $\left.\eta^{2}=0.90\right)$, social competence $\left(F_{(1,38)}=30.86, p<0.001\right.$, partial $\left.\eta^{2}=0.45\right)$ and engagement $\quad\left(F_{(1,38)}=43.81, \quad p<0.001\right.$, partial $\left.\eta^{2}=0.54\right)$. Pairwise comparisons revealed: higher gamer identity levels post-gameplay compared to pre-gameplay (Mdifference=22.3, SE=1.23, 95\%CI: 19.8, 24.8); higher social competence levels post-gameplay compared to pregameplay (Mdifference=2.2, $\mathrm{SE}=0.4,95 \% \mathrm{CI}: 1.4,3.0$ ); and higher engagement post-gameplay compared to pregameplay $(\mathrm{M}$ difference=6.3, $\mathrm{SE}=1.0,95 \% \mathrm{CI}: 4.4,8.3)$.

\subsection{Pre-post Changes by Condition}

A mixed-design ANOVA found an effect of condition (solo/co-located) for social competence $\left(F_{(1,38)}=6.06, p=0.02\right.$, partial $\left.\eta^{2}=0.14\right)$ but not gamer identity $\left(F_{(1,38)}=1.65, P=0.2\right.$, partial $\left.\eta^{2}=0.04\right)$ or engagement $\left(F_{(1,38)}=1.39, p=0.2\right.$, partial $\left.\eta^{2}=0.04\right)$. A greater increase in social competence between pre- and post-gameplay was found for the co-located condition ( $\mathrm{M}=24.5$ vs. 27.7 respectively) compared to the solo condition (mean=24.2 vs. 25.5 respectively). Box plots showing the means and standard error bars for pre- and postgameplay scores for gamer identity, social competence and gamer engagement can be seen in Figure 1.
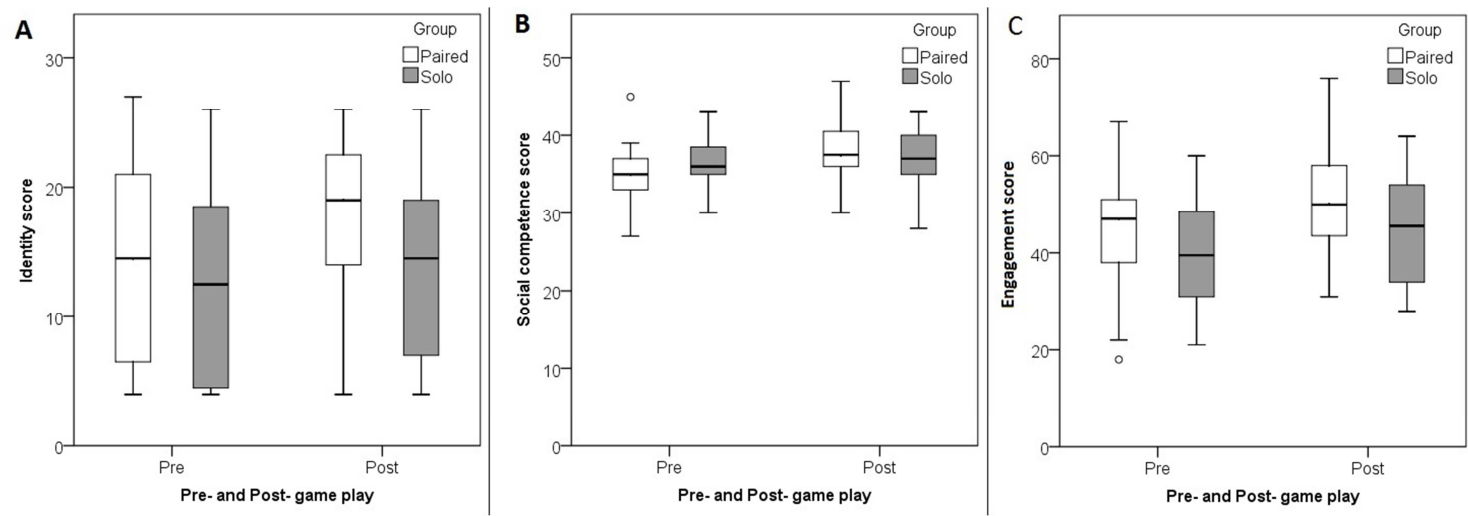

Figure 1. Box plots showing means and standard error bars for gamer identity scores (A), social competence scores (B) and engagement scores (C), pre- and post- gameplay, separated by condition.

\subsection{Multivariate ANOVA}

Results from the multivariate ANOVA showed that gaming engagement was significant in the model $(\mathrm{V}=0.389$, $\left.F_{(2,35)}=11.125, p<0.001\right)$. Separate univariate ANOVAs on the outcome variables revealed a significant effect of engagement on identity $\left(F_{(1,36)}=18.318, p<0.001\right)$ but not social competence $\left(F_{(1,36)}=1.448, p>0.05\right)$. The variables group condition and the condition*engagement interaction term were not significant in the model $(p>0.05)$, indicating that the association between engagement and identity is not influenced by group condition.
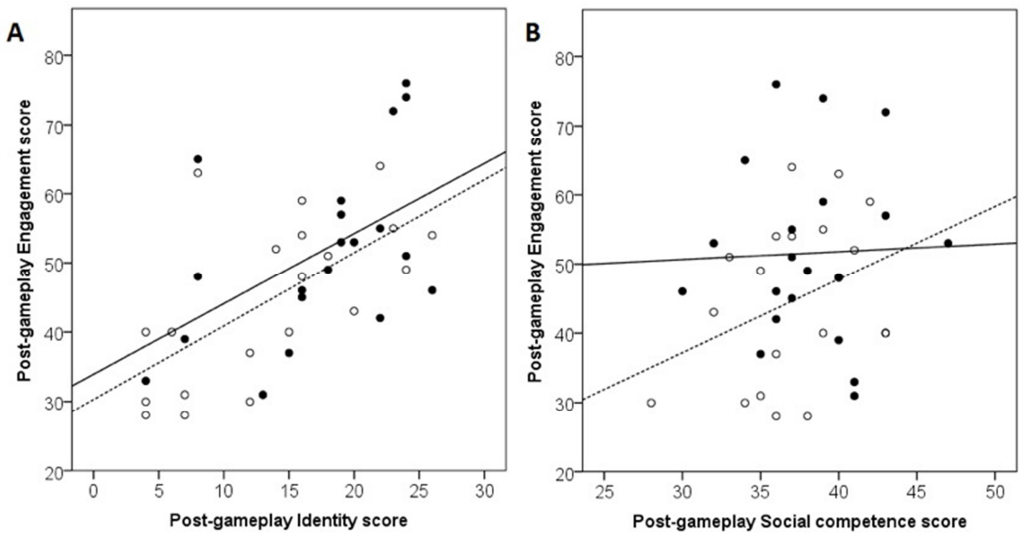

Figure 2. Scatterplots, with lines of best fit, showing the linear association between engagement with (A) gamer identity and (B) social competence, separated by condition. Solid lines and filled circles represent scores for the co-located condition, while dotted lines and empty circles represent scores for the solo condition. 


\section{Discussion}

The current research aimed to establish how experiential engagement in a competitive gaming task varied by physical co-location, and whether this was related to differences in psychosocial impacts for gamer identity and social competence. The main findings and implications are discussed subsequently.

Results suggest physical co-location of another player influences an individual's self-evaluation of social competence, although the level of engagement in gameplay does not appear in itself to be influential to this outcome. The role of physical co-location on social competence appraisals makes practical sense, given that another player affords individuals the opportunity to socially interact which a solo pursuit does not. Venkatesh and Mukherjee argue physical proximity offers multi-sensory immersion and provides users with avenues for spontaneous interacting with others [40]. In contrast, playing online games with the same user group does not offer such rich multi-sensory engagement. However, physical location/presence alone is not enough to guarantee enhanced social interaction; even in co-located game settings. That is, opportunities for such interactions are also defined by social affordances of the game interface itself and spatial characteristics of player's physical environment [18]. Indeed, different games may afford these more than others, and therefore assessing experiential correlates of games is important to understand how and why co-located gaming may have these impacts. The finding that gaming engagement (irrespective of game condition) was not related to social competence outcomes may provide corresponding evidence for this notion. Specifically, it may be the case that greater engagement in (social) play reduces the social affordances available and thus diminishes any impacts on social competence evaluations. This makes conceptual sense since previous findings highlight immersive experiences such as flow are less pronounced in social relative to solo forms of gaming [41], which may suggest that the nature of social gaming reduces opportunities for "engaging" experiences. Therefore, the benefit of social gaming for social competence may derive not through the way players engage in the game itself, but through the co-location opportunity per se. These findings should, however, be interpreted with caution when considering their applications to multiplayer gaming more generally, particularly given the experimental context of the research which may lack the dynamics which social gameplay may bring in real-world gaming [42].

The current results also found increases in all measures from pre to post test. This was the case for gaming engagement, gamer identity and social competence, irrespective of condition. Specifically, this is an encouraging finding, particularly in respect of gamer identity. It suggests even short exposure to gaming tasks (and/or other players within the co-located condition) is sufficient to elicit enhanced perceptions of domain-related identity. Given the psychosocial benefits which aspects of social identity, including gamer identity, have been found to afford [2], the current findings highlight the utility of gaming tasks in fostering these perceptions. It is worth highlighting here that the current findings are relevant to a competitive form of play and raises the question as to how applicable these may be to more cooperative forms of gaming. One may expect, for example, that gamer identity may be more pronounced with cooperative-based tasks in which a commonality of experience to a shared goal would be likely to foster a sense of shared identity [43]. Additionally, cooperative-based tasks which promote shared identity, may also serve a purpose in reducing intergroup conflict within gaming environments, which has been noted as a common experience, particularly for female players in which their competence may be questioned [44, 45]. Therefore, it is both academically and practically fruitful to establish whether the current findings hold the equivalent effects when the task is cooperative in nature.

As with all research, the current study is not without its limitations. Firstly, it cannot be established how familiar participants within the co-located conditions may have experienced each other. That is, it is conceivable that more acquainted co-participants would have interacted more fully and have garnered more intense experiences [18, 46, 47] which may confound the present findings, particularly in respect of the impact of co-located play on social competence. Second, sample size is a further potential limitation, in which the current findings should be considered with caution.

\section{Conclusion}

The current research established that physical co-presence in gaming can promote players' perceptions of their social competence, with co-location of players having a greater effect on social competence than playing alone, which was not the case for gamer identity of engagement. However, irrespective of social context; gaming tasks themselves also enhance impacts for player identity and a positive relationship was found between engagement and identity. Clearly these are positive impacts which should be acknowledged in respect of the wider conceptions of gaming which tends to shun gaming as socially-isolating, and players as socially inept and incompetent [48, 49]. It is inadequate to claim that gaming is either "good or bad", instead gaming should consider the affordances which specific forms of gaming, in specific contexts, for specific individuals may contribute towards the associated psychological outcomes. The results suggest that location of another player during competitive gameplay improves individuals' self-evaluation of social competence and gaming more generally has positive impacts for players' perceptions of identity. 


\section{References}

[1] Domahidi, E., Breuer, J., Kowert, R., Festl, R., \& Quandt, T. (2018). A longitudinal analysis of gaming-and non-gamingrelated friendships and social support among social online game players. Media Psychology, 21 (2), 288-307.

[2] Kaye, L. K., Kowert, R., \& Quinn, S. (2017). The role of social identity and online social capital on psychosocial outcomes in MMO players. Computers in Human Behavior, 74, 215-223. doi: 10.1016/j.chb.2017.04.030

[3] Ekman, I., Chanel, G., Järvelä, S., Kivikangas, J. M., Salminen, M., \& Ravaja, N. (2012). Social interaction in games: Measuring physiological linkage and social presence. Simulation \& Gaming, 43 (3), 321-338.

[4] Sherry, J., Lucas, K., Greenberg, B. S., \& Lachlan, K. (2006). Video game uses and gratifications as predictors of use and game preference. In P. Vorderer \& J. Bryant (Eds.), Playing video games: Motives, responses, and consequences (pp. 213224). Mahwah, NJ: Erlbaum.

[5] Gajadhar, B. J., De Kort, Y. A., \& Ijsselsteijn, W. A. (2008). Influence of social setting on player experience in digital games. In Proceedings of CHI 2008 Conference, April 5-10, 2008, Florence: Italy

[6] Kaye, L. K. \& Bryce, J. (2014). Go with the flow: The experience and affective outcomes of solo versus social gameplay. Journal of Gaming and Virtual Worlds, 6 (1), 4960. doi: 10.1386/jgvw.6.1.49_1

[7] Kaye, L. K., Monk, R. L., Wall, H. J., Hamlin, I., \& Qureshi, A. W. (2018). The effect of flow and context on in-vivo positive mood in digital gaming. International Journal of Human-Computer Studies, 110, 45-52.

[8] Ducheneaut, N., Yee, N., Nickell, E., \& Moore, R. J. (2006). Alone together?: exploring the social dynamics of massively multiplayer online games. In W. E. Mackay, S. Brewster, \& S. Bødker (Eds.), Proceedings of the SIGCHI Conference on Human Factors in Computing Systems (pp. 407-416). New York, USA: ACM.

[9] de Kort, Y. A. W., Jsselsteijn, W. A., \& Poels, K. (2007). Digital games as social presence technology: Development of the social presence in gaming questionnaire (SPGQ). In Proceedings of the 10th Annual International Workshop on Presence, October 25-27, 2007, Barcelona: Starlab 2007, 195-203

[10] Markus, H. (1978). The effect of mere presence on social facilitation: An unobtrusive test. Journal of Experimental Social Psychology, 14 (4), 389-397.

[11] Paulus, P. B. (Ed.). (2015). Psychology of group influence (Vol. 22). Psychology Press.

[12] Bowman, N. D., Weber, R., Tamborini, R., \& Sherry, J. (2013). Facilitating game play: How others affect performance at and enjoyment of video games. Media Psychology, 16 (1), 39-64.

[13] Eastin, M. S. (2007). The influence of competitive and cooperative group game play on state hostility. Human Communication Research, 33, 450-466.

[14] Ratan, R. A., Chung, J. E., Shen, C., Williams, D., \& Poole, M. S. (2010). Schmoozing and smiting: Trust, social institutions, and communication patterns in an MMOG. Journal of Computer Mediated Communication, 16, 93-114.
[15] Cairns, P., Cox, A. L., Day, M., Martin, H., \& Perryman, T. (2013). Who but not where: The effect of social play on immersion in digital games. International Journal of HumanComputer Studies, 71 (11), 1069-1077.

[16] Gajadhar, B. J., De Kort, Y. A., \& Ijsselsteijn, W. A. (2008). Shared fun is doubled fun: player enjoyment as a function of social setting. In Fun and games (pp. 106-117). Springer Berlin Heidelberg.

[17] Gajadhar, B. J., de Kort, Y. A. W., \& IJsselsteijn, W. A. (2009). Rules of engagement: influence of co-player presence on player involvement in digital games. International Journal of Gaming and Computer-Mediated Simulations, 1 (3), 14-27. http://dx.doi.org/10.4018/jgcms.2009070102.

[18] De Kort, Y. A. W., IJsselsteijn, W. A., \& Gajadhar, B. J. (2007). People, Places, and Play: A research framework for digital game experience in a socio-spatial context. DiGRA 2007 Proceedings'Situated Play, 823-830.

[19] Holmes, R. M., \& Pellegrini, A. D. (2005). Children's social behavior during video game play. In: J. Raessens \& J. Goldstein (eds.), Handbook of Computer Game Studies. Cambridge, MA: MIT Press, pp. 133-144.

[20] Calvert, (2005). Cognitive effects of video games. In: J. Raessens \& J. Goldstein (eds.), Handbook of Computer Game Studies. Cambridge, MA: MIT Press, pp. 125- 131.

[21] Gunter, B. (2005). Psychological effects of video games. In: J. Raessens \& J. Goldstein (eds.), Handbook of Computer Game Studies. Cambridge, MA: MIT Press, pp. 145-160.

[22] Brockmyer, J. H., Fox, C. M., Curtiss, K. A., McBroom, E., Burkhart, K. M., \& Pidruzny, J. N. (2009). The development of the Game Engagement Questionnaire: A measure of engagement in video game-playing. Journal of Experimental Social Psychology, 45 (4), 624-634.

[23] Cheng, M. T., Lin, Y. W., She, H. C., \& Kuo, P. C. (2017). Is immersion of any value? Whether, and to what extent, game immersion experience during serious gaming affects science learning. British Journal of Educational Technology, 48 (2), 246-263.

[24] Csíkszentmihályi, M. (1990). Flow: The psychology of optimal experience. New York: Harper and Row.

[25] Jin, W., Sun, Y., Wang, N., \& Zhang, X. (2017). Why users purchase virtual products in MMORPG? An integrative perspective of social presence and user engagement. Internet Research, 27 (2), 408-427.

[26] Black, D. (2017). Why can i see my avatar? embodied visual engagement in the third-person video game. Games and Culture, 12 (2), 179-199.

[27] Wiebe, E. N., Lamb, A., Hardy, M., \& Sharek, D. (2014). Measuring engagement in video game-based environments: Investigation of the User Engagement Scale. Computers in Human Behavior, 32, 123-132.

[28] Soutter, A. R. B., \& Hitchens, M. (2016). The relationship between character identification and flow state within video games. Computers in Human Behavior, 55, 1030-1038.

[29] Tamborini, R., \& Skalski, P. (2006). The role of presence in the experience of electronic games. Playing video games: Motives, responses, and consequences, 225-240. 
[30] Przybylski, A. K., \& Mishkin, A. F. (2016). How the quantity and quality of electronic gaming relates to adolescents' academic engagement and psychosocial adjustment. Psychology of Popular Media Culture, 5 (2), 145.

[31] Lim, S., \& Reeves, B. (2010). Computer agents versus avatars: responses to interactive game characters controlled by a computer or other player. International Journal of HumanComputer Studies, 68 (1-2), 57-68.

[32] Kowert, R., Vogelgesang, J., Festl, R., \& Quandt, T. (2015). Psychosocial causes and consequences of online video game play. Computers in Human Behavior, 45, 51 - 58. doi: 10.1016/j.chb.2014.11.074

[33] Tajfel, H., \& Turner, J. (1979). An integrative theory of intergroup conflict. In J. A. Williams, \& S. Worchel (Eds.), The social psychology of inter-group relations (pp. 33-47) (Belmont, CA: Wadsworth).

[34] Kaye, L. K. (2014). Football manager as a persuasive game for social identity formation. In D. Ruggiero (Ed.), Cases of societal effects of persuasive games (pp. 1-17). IGI Global. http://dx.doi.org/10.4018/978-1-4666-6206-3.ch001.

[35] Kowert, R. (2015). Video games and social competence. New York: Routledge.

[36] Fraser, J., Shane-Simpson, C., \& Asbell-Clarke, J. (2014). Youth science identity, science learning, and gaming experiences. Computers in Human Behavior, 41, 523-532.

[37] Visser, M., Antheunis, M. L., \& Schouten, A. P. (2013). Online communication and social well-being: How playing World of Warcraft affects players' social competence and loneliness. Journal of Applied Social Psychology, 43 (7), 1508-1517.

[38] Doosje, B., Ellemers, N., \& Spears, R. (1995). Perceived intragroup variability as a function of group status and identification. Journal of experimental social psychology, 31 (5), 410-436.

[39] Riggio, R. E., \& Canary, D. R. (2003). Social skills inventory manual (2nd ed.). Redwood City, CA: MindGarden.

[40] Venkatesh, A., \& Mukherjee, S. (2006). Video Games as Nurturing Technology: Relational and Bonding Issues. In: A. Elliott, S. D. Mainwaring, P. Sengers, \& A. Woodruff (organizers): Nurturing Technologies in the Domestic
Environment: Feeling Comforted, Cared for, and Connected at Home. UbiComp 2006 Workshop, September 18, 2006.

[41] Kaye, L. K. (2016). Exploring flow experiences in cooperative digital gaming contexts. Computers in Human Behavior, 55, 286-291. doi: 10.1016/j.chb.2015.09.023

[42] Kaye, L. K., Monk, R. L., \& Hamlin, I. (2018). "Feeling appy?": Using app-based methodology to explore contextual effects on real-time cognitions, affect and behaviours. In C. Costa \& J. Condie (Eds.), Doing research in and on the digital: Research methods across fields of inquiry. Taylor and Francis Ltd

[43] Hogg, M. A. (2016). Social Identity Theory. In S. McKeown, R. Haji \& N. Ferguson (Eds.), Understanding Peace and Conflict Through Social Identity Theory (pp 3-17). Switzerland: Springer

[44] Jenson, J., Fisher, S., \& de Castell, S. (2011). Disrupting the gender order: Leveling up and claiming space in an afterschool video game club. International Journal of Gender, Science and Technology, 3 (1), 148-169.

[45] Kaye, L. K., \& Pennington, C. R. (2016). "Girls can't play": The Effects of Stereotype Threat on Females' Gaming Performance. Computers in Human Behavior, 59, 202-209. doi: $10.1016 /$ j.chb.2016.02.020

[46] Ravaja, N., Saari, T., Turpeinen, M., Laarni, J., Slaminen, M., \& Kivikangas, M. (2006). Spatial presence and emotions during video game playing: Does it matter with whom you play? Presence: Teleoperators and Virtual Environments, 15, 381-392.

[47] Waddell, J. C. \& Peng, W. (2014). Does it matter with whom you slay? The effects of competition, cooperation and relationship type among video game players. Computers in Human Behavior, 38, 331-338. doi: 10.1016/j.chb.2014.06.017

[48] Kowert, R., Griffiths, M. D., \& Oldmeadow, J. A. (2012). Geek or Chic? Emerging Stereotypes of Online Gamers. Bulletin of Science, Technology \& Society, 32 (6), 471-479. http://doi.org/10.1177/0270467612469078

[49] Kowert, R., \& Oldmeadow, J. A. (2012). The Stereotype of Online Gamers: New Characterization or Recycled Prototype. In Proceedings of Nordic DiGRA: Games in Culture and Society Conference. Tampere, Finland: DiGRA. 